\title{
A.I taking over a global climate mapping platform
}

Technology has come a long way from man starting fire, to being a part of a global movement. Technology is all consuming and we use in our lives and our work. Everything around us is technology, from the daily tools we utilize such as the toothbrush and toothpaste, to the gadgets we hold in our hands to stay connected to the world, to the video production company that uses computers and CGI effects, cameras and lighting. Technology. It is what holds this world together and now it is being utilized in a global climate mapping platform.

The world has also been changing due to technological advances. Climate change is one of humankind's largest concern and now mathematicians, researchers, engineers and scientists have come together to build a climate mapping platform which will be able to predict not only what will happen tomorrow, in the next city, but all around the world. It will have the capacity to look into the future and see how a country will be affected ten years down the road, using proven Earth sciences of atmospheric science, meteorology, hydrology and agronomy combined with artificial intelligence, imaging and statistics. All this data will go into the software so it will be able to make precise and accurate predictions. It will be able to identify early warning signs of impending storms, strong winds, floods and bushfire. It can even spot water risk and soil changes.

The technology will be utilized by government officials before expanding a plot of land to make sure that it will be an ideal location for whatever building or lot they are planning to develop, it will be used by farmers to determine wield of the year - or even twenty years into the future they can run simulations on the software and adjust the variables in order to help them plan for how best to use their plot of land and realize it's maximum potential.

It can be used to forecast weather and how the land will be affected. This technology is currently being developed and should be ready for trials in 2020. It will definitely be helpful in risk management. Insurers can use it to set their premiums for the next 12 months while depending on the data that it provides on potential floods, droughts, or even natural disasters. With enough data, it might evolve to predict certain trends in civilization. For instance, the Syria civil war in 2011 was due to the lack of access to freshwater due to the drought. By being able to anticipate any problems like these in the future might help prevent political unrest.

The technology is set to be available to the public so everyone who needs it will be able to benefit from the real-time feedback on climate prediction. It is currently being refined by research companies globally, to assure that the data it receives is well rounded and not biased or 
lacking in any research trends from other climate changes and continental shifts in other parts of the world. 